\title{
Sleep Practices of University Students Living in Residence
}

\author{
Pei Qin ${ }^{1} \&$ Cary A. Brown ${ }^{2}$ \\ ${ }^{1}$ Faculty of Rehabilitation Medicine, University of Alberta, Edmonton, Canada \\ ${ }^{2}$ Department of Occupational Therapy, Faculty of Rehabilitation Medicine, University of Alberta, Edmonton, \\ Canada
}

Correspondence: Cary A. Brown, 2-64 Corbett Hall, University of Alberta, Edmonton, Canada, T6G 2G4.

Received: August 8, 2017

doi:10.5430/ijhe.v6n5p14
Accepted: August 28, 2017

Online Published: August 30, 2017

URL: https://doi.org/10.5430/ijhe.v6n5p14

\begin{abstract}
Sleep plays an important role in both students' academic and personal life. Despite widespread sleep problems among young adults, few studies focus on higher education students living in campus residence. This study investigated residence-living students' sleep patterns, sleep promoting practices, sources of help seeking, and preferred ways to receive information. Results highlighted that $66.8 \%$ of the participants did not think they had enough sleep. However, only $18.9 \%$ of the students sought help. The campus residence sleep environment was challenging for many students. Problems such as uncomfortable room temperature and noise were frequently identified. Students used different strategies to promote sleep such as opening the window, reading books, listening to music, and alcohol. Efficient knowledge translation activities to facilitate the understanding of sleep physiology and sleep problem solving are needed at both the student and the organizational planning/administration level. Further studies focusing specifically on sleep environment scans and developing best practice guidelines are recommended.
\end{abstract}

Keywords: Campus residence, Higher education students, Sleep strategies, Sleep environment, University, College

\section{Introduction}

For many young adults, attending higher education (HE) institutions and living on campus is their first foray into independence and self-care. It is a critical life period to both adopt and discontinue behaviors and self-care activities related to health (Viner et al., 2012). Sleep is one such self-care challenges and poor sleep is a potential obstacle to success for HE students (Orzech, Salafsky, \& Hamilton, 2011; Sexton-Radek \& Hartley, 2013; Gaultney, 2016). A study of health-risk behaviors among post-secondary students across eight Canadian HE institutions showed that 75.6\% of students did not get adequate sleep (Kwan et al., 2013). While sleep deficiency is clearly linked to academic performance and overall health, $78.5 \%$ of Canadian students in a North American wide study of HE students report that they had not received information about sleep difficulties from their colleges or universities (American College Health Association [ACHA], 2016).

The consequences of sleep deficiency are numerous. Sleep deficient HE students' have poorer academic performance, increased risk-taking behaviors and experience more problems with mental health (Hershner \& Chervin, 2014). For example, Orzech et al. (2011) found a positive correlation between grade point average (GPA) and sleep quality. Students who had pulled "an all-nighter" had a significantly lower GPA compared with those who did not. Gaultney's study (2016) found that first-year students at risk of sleep disorders were more likely to drop out of school over the undergraduate 3-year period. They suggested that sleep deficient students were at greater risk for depression, lower achievement, poor motivation, and decreased self-efficacy, all potentially having an indirect effects on GPA. Additionally, sleep deficiency is considered a risk factor for many other health conditions, including obesity, diabetes, and heart disease, such that unresolved sleep problems while a student can have long term effect (Hereford, 2014).

\subsection{Specific Aims}

Higher education student sleep practices in residence is an under-studied area. Knowing students sleep information preferences and sleep practices will help us develop more targeted interventions. This paper begins that process and presents study findings about residence-living students' self-reported sleep patterns, sleep promoting practices, sources of help seeking, and preferred ways to receive information. The study will also help support future research 
to develop and test targeted environment changes in HE residential settings and sleep education intervention strategies for students.

\section{Literature Review}

Sleeping in residence can be a challenging experience for students because of the unique environment, roommates' different habits, and uncomfortable bedroom temperature (Sexton-Radek \& Hartley, 2013). A study showed sleep difficulty was one of the predictors of stress for students who live in residence (Dusselier et al., 2015). Although this phenomenon among HE students is prominent, large-scale studies to help health providers or educators understand the residence-living students' sleep issues are lacking. To the best of the authors' knowledge, only one group of researchers in the University of St. Thomas in the U.S. have conducted an environmental scan on North American HE campuses (Broek et al., 2014).

\subsection{Contributing Factors to Sleep Deficiency and help Seeking Behaviours}

Physiologically, young adults tend to have delayed sleep patterns because of circadian rhythm and homeostatic change during development which contribute to decreased sleep drive and later bedtime. These changes are often in conflict with school and social schedules that students will prioritize over sleep. Consequently, young people may have irregular sleep schedules and insufficient sleep (Crowley, Acebo, \& Cardkadon, 2007; Hershner \& Chervin, 2014).

Higher education students' mental health and stress have been identified as major issues (Laidlaw, McLellan, \& Ozakinci, 2016). Laidlaw et.al demonstrated two major sources of stress: short-term academic workload and long-term anxiety related to independent adult life. Mental health and sleep deficiency appear to have a bi-directional relationship such that poor sleep increases the risk of certain mental health conditions and vice versa (Pandi-Perumal \& Kramer, 2010). Similar to mental health, a bi-directional relationship has been demonstrated between substance use and sleep. In other words, using substances with sedating and soporific effects can affect circadian rhythms and directly cause sleep disturbances; conversely, sleep difficulties appear to increase the risk of substance misuse (Hasler et al., 2012; Wong, Robertson, \& Dyson 2015). Metha et al. (2014) concluded from their study of college students in the U.S., that there was an association between friendship and substance use. New friendships while living in residence may contribute to new patterns of substance use and a subsequent increased risk of sleep deficiency. Sleep deficient persons demonstrate decreased insight and increased risk taking behavior (Hershner \& Chervin, 2014), which can further compound the negative outcomes arising from the interaction of substance use and sleep deficiency.

For some students sleep deficiency is a problem they bring to campus living with them. For others, the residential living situation presents new, previously unexperienced, challenges. While campuses offer resources to help address health, it appears that students' help-seeking behaviours are not necessarily extensive. For example, a survey involving 275 U.S. and Canadian university and college counseling centers showed that only $11 \%$ of enrolled students sought assistance during the year (Gallagher, 2015). This is concerning given that $48.4 \%$ of HE students in a large North American survey carried out by the ACHA, reported they had 3 or more personal situations that were very difficult to handle, and that $26.9 \%$ of participants included sleep difficulties in their responses (ACHA, 2014). Further studies indicate that HE students, especially first years, did not want to disclose problems and less than $10 \%$ wanted to talk with counselors about personal health issues (Noel-Levitz Inc., 2011). Similarly, a study of international and ethnic minority students at a U.S. university, found that that these students were less likely to utilize counseling center compared to the local, predominantly white, students (Yakushko, Davison \& Sanford-Martens, 2008). It is difficult to know how this lack of help-seeking relates to sleep deficiency; it may be that students do not see sleep problems as a health issue, or that they feel there is little that can be done and so are not motivated to look for assistance. More research is needed to develop a more nuanced understanding.

Finally, temperature, light exposure and sound are frequently overlooked detrimental effects on sleep (Li \& Lian, 2016; Chellappa et al., 2013; Mestre, 2008). Student accommodations can be challenging environments with high-density living, little choice of roommate, and limited control over noise and/or temperature. The relationship between sleep-wakefulness and temperature has been investigated repeatedly. Both sleep onset and maintenance are related to core body temperature (Tcore) and skin temperature. More specifically, sleep onset coincides with the decline in Tcore and increase of skin temperature. Increasing Tcore can promote wakefulness (Van Someren, 2000). According to the National Sleep Foundation (NSF), the recommended room temperature for effective sleep is around $18^{\circ} \mathrm{C}(\mathrm{NSF}, 2017)$. Blue spectrum light, which suppresses melatonin production necessary for sleep onset, is emitted by electronic devices such as laptops, tablets and smartphones (Chellappa et al., 2013). These, and other light emitting sources, are ubiquitous to HE student life and we need to know more about any strategies students use to decrease sleep inhibiting exposure before bed. 


\section{Methods}

We developed a survey to answer our research aim of determining residence-living students' self-reported sleep patterns, sleep promoting practices, sources of help seeking, and preferred ways to receive information. An online survey platform was selected as the most efficient method to collect the data. Compared with traditional survey methods such as postal mail and interview, online survey is a fast, cost-effective tool, able to reach large and widely distributed samples. Additionally, using direct data entry can reduce variations and bias potentially introduced by from research interviewers (Sue \& Ritter, 2012). The survey invitation was forwarded to the 3041 students (1572 females and 1469 males, aged from 16 to 52 years old) who were living in a University of Alberta residence (dormitory, apartment, house, and fraternity styles of residence) during the study period.

\subsection{Sample}

The anonymous online survey, hosted on the FluidSurvey ${ }^{(\mathrm{RT})}$ platform, was conducted in April 2016. Participants were recruited through direct emails from the campus residence services at the University of Alberta, as well as posters in high traffic areas in the residences. All students living in residence received a reminder email after two weeks. The email and poster had the URL and the Quick Response (QR) code image linking to the survey directly.

\subsection{Survey}

The survey included four sections. To collect basic demographic information, the survey asked participants' age, gender, undergraduate/graduate program, and the residence type they lived in. In the section of self-reported sleep duration and quality, participants provided their average sleep length and whether they got enough sleep. In the section of sleep help-seeking and sleep promoting strategies, participants were asked whether they sought help with their sleep, the person they asked, and the advice they received. Participants also chose any of the sleep promoting strategies they used from a list and ranked the strategies by frequency ("always"- 5-7 nights/week; "often"- 1-4 nights/week; "sometimes"- <3 nights/month). Participants were not asked to comment on the strategies they had never used. The 16 strategies in the list were identified from the background literature review as activities students engaged in to promote sleep. The last section of the survey were questions about students' preferred ways to receive information. Details of each item are presented in the following paragraphs.

\subsection{Data Analysis}

The quantitative data in this study was exported to SPSS (Version 23) for descriptive analysis. Chi-square test was used to analysis the correlation. The survey also included free-text responses. However, the answers that participants provided were often short, with no full sentences. These short-answered questions in surveys can be a problem because such data is neither exactly quantitative nor qualitative (O'Cathain \& Thomas, 2004). One particular issue is that the in-depth answers provided by participants may be interpreted with more weight by researchers than those of participants providing only brief responses. Consequently, the brief responses may be overlooked. O'Cathain and Thomas (2004) concluded that the numbers of respondents are important to report for this type of data. Thus, following repeated readings by both researchers and discussion to resolve any differences, we summarized the open-ended text responses into categories according to the main ideas and ranked these categories by the frequency with which responses appeared in each category was.

\subsection{Ethics}

All data collection was anonymous and submission of the survey was considered as consent to participate. The study was approved by the Health Research Ethics Board of the University of Alberta.

\section{Results}

\subsection{Demographics}

There were 292 students who lived in the campus residence participating in the survey (Table 1). They accounted for $9.6 \%$ of all the residence-living students. According to the data provided by the residence service at the campus, this sample distribution was representative of the different residence types at the University of Alberta.

\subsection{Self-reported Hours of Sleep and Quality of Sleep}

Participants were asked to report their average weeknight hours of sleep selecting from the multiple choices options of "less than 4.5 hours", " 4.5 to 6.4 hours", " 6.5 to 8 hours", and "more than 8 hours". Statistical analysis by Chi-square test showed that there was no correlation between average weeknight sleep duration and age, nor the participants' education programs (undergraduate, graduate, and Ph.D.). When students were asked whether perceived they had enough sleep, only $33.2 \%$ participants (97/292) thought that they had enough sleep while $66.8 \%$ thought 
they did not (195/292). Students who reported less than 6.5 hours of sleep were more likely to state that they had not have enough sleep $(\mathrm{df}=1, \mathrm{X} 2=56.60, \mathrm{p}<.000)$.

Table 1. Demographics and sleep patterns

\begin{tabular}{|c|c|c|c|c|c|}
\hline \multirow{2}{*}{$\begin{array}{l}\text { Program } \\
(\mathrm{n}=292)\end{array}$} & \multicolumn{2}{|c|}{ Undergraduate } & Graduate & & $\mathrm{PhD}$ \\
\hline & \multicolumn{2}{|c|}{$242(82.9 \%)$} & $26(8.9 \%)$ & & $22(7.5 \%)$ \\
\hline \multirow{2}{*}{$\begin{array}{l}\text { Gender } \\
(\mathrm{n}=292)\end{array}$} & \multicolumn{2}{|c|}{ Female } & Male & Non-1 & jinary/Unstated \\
\hline & \multicolumn{2}{|c|}{$186(63.7 \%)$} & $87(29.8 \%)$ & & $19(6.5 \%)$ \\
\hline \multirow{2}{*}{$\begin{array}{c}\text { Age } \\
(\mathrm{n}=292)\end{array}$} & \multicolumn{2}{|c|}{$\leq 25$ years } & 26-35 years & & $\geq 36$ years \\
\hline & \multicolumn{2}{|c|}{$256(87.7 \%)$} & $28(9.6 \%)$ & & $8(2.7 \%)$ \\
\hline \multirow{2}{*}{$\begin{array}{l}\text { Residence } \\
\text { type } \\
(n=292)\end{array}$} & $\begin{array}{l}\text { Dormitory- } \\
\text { Share room }\end{array}$ & $\begin{array}{l}\text { Dormitory- } \\
\text { Single room }\end{array}$ & $\begin{array}{l}\text { Apartment- } \\
\text { Bachelor }\end{array}$ & $\begin{array}{l}\text { Apartment- } \\
1 \text { bedroom }\end{array}$ & $\begin{array}{l}\text { Apartment- } \\
\geq 2 \text { bedroom }\end{array}$ \\
\hline & $31(10.6 \%)$ & $147(50.3 \%)$ & $29(9.9 \%)$ & $12(4.0 \%)$ & $72(24.6 \%)$ \\
\hline \multirow{2}{*}{$\begin{array}{l}\text { Sleep hours* } \\
\quad(\mathrm{n}=291)\end{array}$} & $<4.5$ hours & 4.5-6.4 hours & \multicolumn{2}{|l|}{$6.5-8$ hours } & $>8$ hours \\
\hline & $6(2.1 \%)$ & $88(30.2 \%)$ & $172(58.8 \%)$ & & $26(8.9 \%)$ \\
\hline \multirow{2}{*}{$\begin{array}{c}\text { Perceived } \\
\text { enough sleep } \\
(n=292)\end{array}$} & \multicolumn{2}{|c|}{ Yes } & \multicolumn{3}{|c|}{ No } \\
\hline & \multicolumn{2}{|c|}{$33.2 \%$} & \multicolumn{3}{|c|}{$66.8 \%$} \\
\hline
\end{tabular}

\subsection{Help-Seeking Behaviors}

There were 275 participants who responded to the question, "If you think you do not get enough sleep, have you ever asked anyone for help with your sleep?" Only 52 (18.9\%) of students said "yes". However, when participants were asked, "If yes, who did you ask?", 83 answers in total were provided (some participants listed more than one person they had asked). As described previously, open-ended question responses were collapsed into four categories. The categories by frequency were: Doctor/ Counselor/ Other health profession: 32.5\% (27/83); Family/ Significant other: 28.9\% (24/83); Friend/ Teacher/ Coach/ Residence Assistant: 28.9\% (24/83); and Internet: 9.6\% (8/83).

The data shows that, although many students were concerned that they did not get enough sleep, few sought advice. Among the students who asked for help with their sleep, most asked people around them, such as families and friends. These two categories together accounted for $57.8 \%$ of responses. Markedly, only 27 students (32.5\%) sought help from a health professional.

\subsection{Types of Advice Received}

There were 58 different answers given to the open-ended question "If you sought help, what advice were you given?" Most of the suggestions were related to sleep hygiene $(70.7 \%, 41 / 58)$, followed by a medication recommendation (such as melatonin). The details are listed in Table 2 in descending order of frequency of mention. 
Table 2. Types of advice received

\begin{tabular}{lc}
\hline Advice & Times mentioned \\
\hline Sleep hygiene- including: & 41 (4 not specified) \\
Keep to a routine & 10 \\
Relax/ engage in calming activity before bed & 7 \\
Avoid electronics before bed & 5 \\
Avoid food/ have warm drinks before bed & 5 \\
Exercise in the daytime & 4 \\
Only use the bed for sleep & 3 \\
Medication & 14 \\
Environment change (no specifics) & 3 \\
Use earplugs & 2 \\
Sleep more & 1 \\
\hline
\end{tabular}

\subsection{What Students do to Help Themselves Sleep}

Participants ranked each of the 16 strategies in the survey by frequency. Table 3 shows the results for students' having ever used a specific sleep promoting strategy ranked in descending order (i.e. sum of respondents selecting "always", "often", and "sometimes"). The percentages in the table were calculated by the number in each category out of the total responses (excluding those participants who never use the respective strategy).

"Turn down the heat/open the window" was the most popular strategy, reported as having ever been used by $72.6 \%$ (212/292) participants. This is also the most highly ranked strategy in the categories "always" and "often". Other frequently used strategies include "read a book" $(67.8 \%, 198 / 292)$, "listen to music" (67.4\%, 197/292), "watch TV" $(62.3 \%, 182 / 292)$, and "use white noise" $(54.1 \%, 158 / 292)$. Over one-third of students reported some use of alcohol $(43.5 \%, 127 / 292)$, cigarettes $(36.6 \%, 107 / 292)$, and recreational drugs $(36.3 \%, 106 / 292)$ to help them sleep. While most participants used these three strategies less than three times per month $(85 \%, 96.3 \%$, and $93.4 \%$ respectively), three participants used alcohol, two participants smoked cigarettes, and one participant used recreational drugs 5-7 times per week.

\subsection{Other Sleep Strategies}

There were also 94 participants who provided "other" sleep strategies. Some of the strategies aligned with the 16 strategies listed in the survey, but we did not collapse these "other" responses into the above section as we had no mechanism to check our interpretation. From the original 94 responses, 67 different strategies emerged. We categorized the responses into eight groups which are listed in descending order of the frequency with which they were mentioned (Table 4). 
Table 3. Students' sleep strategies

\begin{tabular}{|c|c|c|c|c|}
\hline Strategy & $\begin{array}{c}\text { always (5-7 } \\
\text { times / week) }\end{array}$ & $\begin{array}{c}\text { often }(1-4 \\
\text { times/ week) }\end{array}$ & $\begin{array}{c}\text { sometimes (less than } 3 \\
\text { times/ month) }\end{array}$ & $\begin{array}{c}\text { Total } \\
\text { Responses }\end{array}$ \\
\hline $\begin{array}{l}\text { turn down the heat or } \\
\text { open a window }\end{array}$ & $77(36.3 \%)$ & $77(36.3 \%)$ & $58(27.4 \%)$ & 212 \\
\hline read a book & $17(8.6 \%)$ & $42(21.2 \%)$ & $139(70.2 \%)$ & 198 \\
\hline listen to music & $24(12.2 \%)$ & $53(26.9 \%)$ & $120(60.9 \%)$ & 197 \\
\hline watch TV & $32(17.6 \%)$ & $49(26.9 \%)$ & $101(55.5 \%)$ & 182 \\
\hline white noise & $31(19.6 \%)$ & $22(13.9 \%)$ & $105(66.5 \%)$ & 158 \\
\hline take a warm bath & $17(10.9 \%)$ & $40(25.6 \%)$ & $99(63.5 \%)$ & 156 \\
\hline $\begin{array}{l}\text { take sleep medication- } \\
\text { OTC or herbal }\end{array}$ & $5(3.3 \%)$ & $32(21.3 \%)$ & $113(75.3 \%)$ & 150 \\
\hline $\begin{array}{l}\text { answer outstanding } \\
\text { emails }\end{array}$ & $8(5.5 \%)$ & $23(15.9 \%)$ & $114(78.6 \%)$ & 145 \\
\hline meditate & $7(4.8 \%)$ & $35(24.1 \%)$ & $103(71.0 \%)$ & 145 \\
\hline have sex & $4(2.8 \%)$ & $40(27.8 \%)$ & $100(69.4 \%)$ & 144 \\
\hline write in diary & $4(3.0 \%)$ & $18(13.5 \%)$ & $111(83.5 \%)$ & 133 \\
\hline use a sleep mask & $9(7.1 \%)$ & $10(7.9 \%)$ & $108(85.0 \%)$ & 127 \\
\hline have some alcohol & $3(2.4 \%)$ & $16(12.6 \%)$ & $108(85.0 \%)$ & 127 \\
\hline $\begin{array}{l}\text { take sleep medication- } \\
\text { prescribed }\end{array}$ & $7(5.7 \%)$ & $2(1.6 \%)$ & $113(92.6 \%)$ & 122 \\
\hline smoke a cigarette & $2(1.9 \%)$ & $2(1.9 \%)$ & $103(96.3 \%)$ & 107 \\
\hline use recreational drugs & $1(0.9 \%)$ & $6(5.7 \%)$ & $99(93.4 \%)$ & 106 \\
\hline
\end{tabular}


Table 4. Other sleep strategies used by students

\begin{tabular}{lc}
\hline Strategies & Times mentioned \\
\hline Use earplugs & 15 \\
Workout/ stretching & 13 \\
Use cell phones/ computers & 11 \\
Listen to audio books/ podcast & 6 \\
Make room dark/ be away from blue light & 8 \\
Pray/ mind relax & 6 \\
Warm drinks & 6 \\
Chat with roommates & 2 \\
\hline
\end{tabular}

\subsection{Perceived Need for Additional Information and Preferred Format}

There were $61.3 \%$ (179/292) participants who stated that they would like more sleep information. Their preferences weighted toward emails with information $(58.6 \%, 109 / 186)$. The second preference was for "a handout/ booklet I can read and then contact the author with questions" and only 43 people $(23.1 \%)$ chose this option. Even fewer participants preferred a one-on-one session with a healthcare provider $(7.5 \%, 14 / 292)$ or a recorded webinar $(3.2 \%, 6 / 292)$. Two participants provided other answers such as "Facebook posts" and "a link to a forum to ask question or share advice".

Other participants stated that they did not need extra information about strategies. The content of these students' comments reflected three reasons. Firstly, some stated that they had good sleep and did not need help. Secondly, some doubted whether the strategies would be helpful and refused additional emails that they thought might be of no use. For example, some students thought that it was the noise in the residence and the study load that led to their insufficient sleep. However, they thought it was hard to change such situations. Thirdly, some participants believed they already knew how to manage their sleep or where the problem was. For example, one student said, "I have my own strategies to help me sleep, and they often work quite well."

\subsection{Final Comments}

The final survey question asked participants if there was "Anything else you think we should know about your sleep?" There were 69 sleep-relevant comments made and five major categories emerged. The first category was related to sleep environment in the residences. Forty students $(58.0 \%, 40 / 69)$ expressed their concerns about the sleep environment in the residences. The most common problem was noise, including noise from other residents, traffic, and environment maintenance such as snow clearing. Another concern was the room temperature. Some students commented that applying one sleep strategy, such as opening the window, could also create another problem for sleepmore noise. A few students mentioned that the beds in the dormitories were not comfortable and the curtains were not thick enough to block the light.

A second category was academic pressure and anxiety. Seventeen comments $(24.6 \%, 17 / 69)$ were related to academic pressure such as assignment due dates and exam times. One student said, "It is usually not that I am doing homework. School stressed me out and causes me to think too much before bed".

The third category was related to sleep habits and sleep schedule. Six comments $(8.7 \%, 6 / 69)$ mentioned that keeping a schedule was important to university students. As one student said, "Healthy sleep habits are an integral part of the many interconnected aspects of lifestyle and health which must be addressed in context with other issues and challenges".

The fourth category was related to students' life-style choice. Although few in number (4.3\%, 3/69), these comments are worth noting. Participants reported that activities, such as social events and part time jobs, distract students. Their comments seem to suggest that they chose to sacrifice sleep to make more time for schoolwork and social life. One student commented that "lack of sleep is praised in our culture. Not getting enough sleep is seen as meaning that you are busy and working hard". 
The last category identified that some students $(4.3 \%, 3 / 69)$, even if they perceived a sufficient quantity of sleep, felt that the quality was poor. These students reported that getting tired during the daytime was concerning.

\section{Discussion}

The goal of this survey was to investigate residence-living students' sleep patterns, sleep promoting practices, their sources of help seeking, and preferred ways to receive information. We will discuss the implication of the key findings related to this goal and then present several specific opportunities for HE institutions to promote students' on-campus sleep health.

\subsection{Interpreting Residence-living Students'Sleep Patterns and Behaviors}

Findings of this study showed that $32.3 \%$ reported less than 6.5 hours, including 6 people who had 4.5 hours or less. The cutoff of 6.5 hours is significant because shorter duration of sleep is considered to significantly increase the risk of developing chronic health issues (Colten \& Altevogt, 2006). Although the majority of students reported that they achieved more than 6.5 hours sleep, it was notable that $66.8 \%$ of them thought their sleep was not sufficient. As mentioned previously there are a number of physiological and social challenges that decrease the opportunity for students to achieve sufficient sleep and it appears likely that interventions need to include a range of bio-psycho-social strategies.

It is of concern that few students sought help even though they thought their sleep was insufficient. Considering that the majority of participants in this study were undergraduate students in their first year at the university, there may be several reasons for this result. Congruent with the literature about HE student help seeking behaviour, gaps may exist between the utilization of $\mathrm{HE}$ counseling and health centers and the level of need around the campus. Additionally, from the comments provided by participants in our study, it appeared that some students, while they knew what the problem was, felt they had limited control over the issues affecting their sleep, especially within the residence environment.

Several particular findings regarding the sleep strategies employed by participants in this study warrant further discussion. First, some students reported using alcohol, recreational drugs, and/or cigarettes as sleep strategies. As mentioned in the preceding literature review, substance misuse is related to a range of physical and mental health problem, including sleep deficiency. Coupled with proximity to friends living in the same residence, the opportunity and peer encouragement for substance use may be an increased risk to sleep efficiency for students living in residence.

Second, the findings did not answer the question of whether students used the simple sleep strategies they reported correctly; in other words, we did not determine how they practiced the strategies they believed helped with sleep. Some of the frequently practiced strategies may have an unanticipated and undesired effect on sleep. For example, students reported taking over the counter (OTC) and prescription medication as a sleep strategy. Since many students looked for help from families and friends instead of health professionals, the risk of taking medication improperly cannot be neglected. A second example are the strategies, reported by many students, of reading a book and watching TV to ease into sleep. However, TVs and e-books may also increase exposure to blue spectrum light, therefore suppressing melatonin production and altering circadian rhythm (Chellappa et al., 2013).

Thirdly, as noted previously, student accommodations in HE can be challenging environments with little control available to the student. The survey showed that the most frequently employed strategy was "turn down the heat" or "open the window". The high frequency of statements about this strategy appears to reflect that, for many participants, the indoor temperature in the campus residence was not comfortable for sleep. These types of issues often require policy and design level intervention, institutions and policy makers have a duty of care to provide sleep conducive residence environments. However, literature review showed that institutional living design guidelines for campus residence are sparse and attention to this unmet need is required. The following section outlines opportunities to promote a good sleep environment for HE students.

\subsection{Opportunities to Improve the Sleep of Students Living in Residence}

Opportunities for sleep interventions can be grouped into three categories: actions that residence services are responsible for, those that are the responsibility of campus health service, and, thirdly, those that are students' responsibility. The three categories can of course interact with each other but will be discussed here as discrete categories for clarity and organizational purposes.

Residence services plays an important role in students' health and can be a bridge between students and other units on campus. Currently, there appears to be a significant gap between campus residence building regulations and students' sleep needs. For example, although general building regulations such as the Minimum Housing and Health Standards 
in the province of Alberta, Canada (Government of Alberta, 2012) establishes basic requirements, it makes no specific mention of conditions necessary to ensure a good sleep environment. For example, the standards state that room temperature is required to be at least 22 degrees Celsius in winter. However, there is no recommendation for the maximum allowable temperature. Research supports a recommended sleep temperature between 18-22 Celsius and highlights that temperatures above 22 degrees Celsius interferes with the drop in core body temperature required for sleep onset and circadian regulation (Lan \& Lian, 2016). Students may experience sleep-disturbing discomfort if they do not have control over the heating system or the residence does not provide air conditioning in the hot season. Since such building regulations are lacking, environmental interventions in existing buildings will, for the most part, require retrofits. These renovations can be very costly and it is important for university residence service to carry out environmental scans of campus residences using evidence-based sleep environment guidelines to improve students' living experience and wellbeing.

As mentioned in the Introduction section, researchers in the U.S. conducted sleep environment scans in more than fifty HE campuses (Broek et al., 2014). They proposed several pathways to improve campus residence sleep environments. For example: working with a university's department of sustainability to align sleep-friendly and energy efficient retrofits; improving roommate matching for environmental preferences by asking specific sleep questions on the residence application form; providing more sleep hygiene products in campus stores; and moving vending machines in residence that sell energy drinks away from bedrooms. The authors reported that $75 \%$ colleges and universities who participated in the scan rethought the campus sleep environment in the residence and over half of the institutions planned to make changes in some aspects.

Residence services can also send sleep-promoting information through direct emails or electronic news, which, according to the participants in our study, is the preferred way to receive information. Posters and brochures with small sample products that can promote sleep posted in the residence halls, cafeteria line-ups, or beside elevators where students are waiting can be another efficient way to maximize the likelihood of sleep education information being noticed and read (Marketing Charts, 2014; Ward \& Hawthorme, 1994).

The second category of actions are the responsibility of campus health centers and counseling service. Questions related to sleep issues, such as using medication, could be embedded into other forms of health and wellbeing monitoring and counseling. These types of screening questions can alert service providers to a potential need for follow-up assessment, intervention, and, at a minimum, to offer additional sleep education. Outreach activities around campus can bring health professionals, staff and students together to provide them all with evidence-based sleep knowledge and useful strategies. This would help address students' hesitation to seek help at student health services (Sanchez \& King-Toler 2007; Marks \& McLaughlin, 2005). Educating course instructors and professors about the negative impact for students who sacrifice sleep to meet assignment deadlines and study for exams is also important. An example of a pragmatic strategy would be to set assignment due times one or two hours prior to midnight thus allowing procrastinating students more time for sleep without having to make an active choice to stop working and go to sleep.

The final category relates to students own responsibilities and behaviors. As the findings in our study showed, some students interpreted their lack of sleep as a sign of accomplishment and something of which to be proud. Countering these beliefs is challenging and health service providers need to carry out evidence-based knowledge translation activities to promote students' awareness of sleep biology and self-efficacy to implement pragmatic, effective and targeted sleep strategies. Preferable, sleep awareness campaigns should avoid telling students that what they are doing is wrong and that they need to change. Rather, interventions should take a strengths-based approach, and educate students to critically apply basic sleep science to evaluate and improve any sleep-promoting strategy they currently practice. This approach, as opposed to issuing a list of "do's" and "don'ts", engages and empowers students, thus optimizing their feelings of self-efficacy and ability to direct external influences that affect their sleep. A strength-based approach allows individuals to see solutions rather than barriers (Public Health Ontario [PHO], 2013).

Our study identified several opportunities to apply a strength-based approach to activities students frequently engaged in to promote sleep. For example, reading a book was one of the activities that participants often used to help initiate sleep. However, exposure to electronic light sources before sleep will suppress melatonin production and delay sleep. Using a strength-based approach, instead of telling students they should not read before bed, we would instead educate them about blue-spectrum filtering devices (such as specific goggles, apps, and light bulbs) that reduce exposure to melatonin-suppressing light and minimize the disadvantages of reading before bed. This approach would build on the existing behavior, frame it as a strength, and provide evidence-based information so the strategy would be carried out correctly with less risk to sleep onset. Another example from the study was the high number of participants who 
listened to music to promote sleep onset. A literature review by Harris (2014) determined that music with 60-80 beats per minute combined with other relaxation techniques triggers physiological responses that help relieve stress before bed. Simple smartphone applications (e.g. www.songbpm.com) can determine the beats per minute of a piece of music and whether it is suitable for promoting sleep. Student decisions and habits related to sleep are idiosyncratic, one size does not fit all. We believe that taking a strength-based approach, helping students understand the sleep physiology underpinning their sleep strategies, will allow them to pragmatically and effectively problem-solve depending on their own personal context.

\subsection{Limitations}

This study was conducted at a single university; therefore, the generalizability of findings is limited. Students self-selected and so there was potential for participation bias and the participants may have been more likely to have concerns about their sleep than those who did not take the survey. However, the finding from this study align with other research and highlight the need for intervention. Further study focusing on the residential sleep environment, and testing the outcome of pragmatic environmental modifications, is clearly warranted.

\section{Conclusion}

Sleep experience in campus residences is an under-addressed issue in HE. This study focused on HE students' sleep patterns, help sleep behaviors, and attitudes about receiving information. It is promising that most students reported meeting the basic needs of sleep hours and used some strategies to help their sleep. However, several concerns emerged from the results. Firstly, the majority of students thought they did not have enough sleep. Secondly, few students looked for help with their sleep problems although they stated they would like to receive more information about sleep. Thirdly, the residence sleep environment was a significant factor affecting HE students' sleep. Thus, evidence-based knowledge translation, interaction opportunities between sleep professionals and students, strength-based behavior approaches building on existing strategies, and research-informed campus residence environmental changes have been identified as major pathways to improve the resident living students' sleep. To conclude, Table 5 lists specific recommendations to improve HE students' sleep.

Table 5. Recommendations

Recommendations to Improve the Sleep of HE Students

- Scan the campus residence sleep environment, with particular focus on room temperature, noise, and light. Avoid products that may affect students' sleep such as vending machines containing energy and caffeinated drinks in the residence hall. (Environment scan example:

http://www.stthomas.edu/collegesleep/environment/)

- Increase opportunities for students to interact with residence service and health professionals. Outreach and electronic activities may be more attractive for students than walk-in consultations in the campus health center.

- Integrate sleep screening with other campus-wide health promotions. Information about the negative effect of strategies to self-manage sleep and alertness through substance use (such as drinking alcohol, excessive caffeine, and using recreational drugs), should also be incorporated into these activities.

- Educate other institution staff, such as instructors and departmental chairs, about the impact of sleep deficiency on academic performance. Make policies discourage students from engaging in "all-nighter" activity. For example, avoid setting assignment deadlines at midnight.

. Provide students with evidence-based sleep information through social marketing principles. Use students' preferred methods of receiving information, such as emails and booklets. Free samples of sleep hygiene products can be combined with brochures to attract students.

. Educate students on the physiology behind sleep and sleep strategies. Telling students the 'why' instead of the 'what' is a strength-based approach to help them adjust to sleep strategies depending on their environment context. 


\section{Acknowledgements}

This unfunded study was conduct at the University of Alberta. The distribution of this survey and provision of campus residence data was provided by the University Residence Service Office.

\section{References}

American College Health Association. (2014). National College Health Assessment Fall 2014 Reference Group Executive Summary. Retrieved from http://www.acha-ncha.org/reports_ACHA-NCHAIIb.html

American College Health Association. (2016). National College Health Assessment-II Spring 2016 Canadian Reference Group Data Report. Retrieved from http://www.acha-ncha.org/reports_acha-nchaiic.html

Broek, L., Cunningham, B., Kelly,C., Kielblock,C. \& Prichard, R. (2014). Is your Campus Sleep-Friendly? A Pilot Environmental Sleep Scan for Residential Colleges. Retrieved from http://www.stthomas.edu/collegesleep/environment/

Chellappa, S. L., Steiner, R., Oelhafen, P., Lang, D., Götz, T., Krebs, J., \& Cajochen, C. (2013). Acute exposure to evening blue-enriched light impacts on human sleep. Journal of Sleep Research, 22(5), 573-580. https://doi.org/10.1111/jsr.12050

Colten, H. R., \& Altevogt, B. M. (2006). Sleep disorders and sleep deprivation: An unmet public health problem. Washington, D.C.: National Academies Press.

Crowley, S. J., Acebo, C., \& Carskadon, M. A. (2007). Sleep, circadian rhythms, and delayed phase in adolescence. Sleep Medicine, 8(6), 602-612. https://doi.org/10.1016/j.sleep.2006.12.002

Dusselier, L., Dunn, B., Wang, Y., Shelley, M.,II, \& Whalen, D. F. (2005). Personal, health, academic, and environmental predictors of stress for residence hall students. Journal of American College Health, 54(1), 15-24. https://doi.org/10.3200/JACH.54.1.15-24

Gallagher, R. P. (2015). National survey of college counseling centers 2014. Retrieved from http://d-scholarship.pitt.edu/28178/1/survey_2014.pdf

Gaultney, J. F. (2016). Risk for sleep disorder measured during students' first college semester may predict institutional retention and grade point average over a 3-year period, with indirect effects through self-efficacy. Journal of College Student Retention: Research, Theory \& Practice, 18(3), 333-359. https://doi.org/10.1177/1521025115622784

Government of Alberta (2012) Minimum Housing and Health Standards. Retrieved from http://www.health.alberta.ca/documents/Standards-Housing-Minimum.pdf

Harris, M. J. (2014). Music as a transition for sleep. Occupational Therapy Now, 16(6), 11-13. Retrieved from https://www.caot.ca/site/fm/archivesotnow?nav=sidebar

Hasler, B. P., Smith, L. J., Cousins, J. C., \& Bootzin, R. R. (2012). Circadian rhythms, sleep, and substance abuse. Sleep Medicine Reviews, 16(1), 67-81. https://doi.org/10.1016/j.smrv.2011.03.004

Hereford, J. M. (2014). Sleep and rehabilitation: A guide for health professionals Thorofare, NJ : SLACK Incorporated, 2014. https://doi.org/10.1080/01924788.2017.1275783

Hershner, S. D., \& Chervin, R. D. (2014). Causes and consequences of sleepiness among college students. Nature and Science of Sleep, 6, 73-84. https://doi.org/10.2147/NSS.S62907

Kwan, M. Y. W., Faulkner, G. E. J., Arbour-Nicitopoulos, K., \& Cairney, J. (2013). Prevalence of health-risk behaviours among canadian post-secondary students: Descriptive results from the national college health assessment. BMC Public Health, 13(1), 1-6. https://doi.org/10.1186/1471-2458-13-548

Laidlaw, A., McLellan, J., \& Ozakinci, G. (2016). Understanding undergraduate student perceptions of mental health, mental well-being and help-seeking behaviour. Studies in Higher Education, 41(12), 2156-2168. https://doi.org/10.1080/03075079.2015.1026890

Lan, L., \& Lian, Z. (2016). Ten questions concerning thermal environment and sleep quality. Building and Environment, 99, 252-259. https://doi.org/10.1016/j.buildenv.2016.01.017

Marketing Charts. (2014). Which types of ads do college students pay attention to? Retrieved from http://www.marketingcharts.com/online/which-types-of-ads-do-college-students-pay-attention-to-44096/ 
Marks, L. I., \& McLaughlin, R. H. (2005). Outreach by college counselors: Increasing student attendance at presentations. Journal of College Counseling, 8(1), 86. https://doi.org/10.1002/j.2161-1882.2005.tb00075.x

Mestre, V., National Research Council, Airport Cooperative Research Program, \& United States (2008). Effects of aircraft noise : Research update on selected topics. Washington, D.C.: Transportation Research Board. Retrieved from http://onlinepubs.trb.org/onlinepubs/acrp/acrp_syn_009.pdf

Metha, C. M., Jacqueline, A., Rebecca, D., \& Brian, J. A. (2014). Associations between mixed-gender friendships, gender reference group identity and substance use in college students. Sex Roles, 70(3-4), 98-109. https://doi.org/10.1007/s11199-013-0334-8

National Sleep Foundation. (2017). A great night's sleep can depend on the comfort you feel in your bedroom environment Retrieved from https://sleepfoundation.org/bedroom/touch.php

Noel-Levitz, I. (2011). Addendum by Race/Ethnicity: National freshman attitudes report, 2011. National research study. $\quad$ Noel-Levitz,

Inc. https://www.noellevitz.com/documents/shared/Papers_and_Research/2011/FreshmanAddendum2011.pdf

O'Cathain, A., \& Thomas, K. J. (2004). "Any other comments?" open questions on questionnaires -- a bane or a bonus to research? BMC Medical Research Methodology, 4, 25-7. https://doi.org/10.1186/1471-2288-4-25

Orzech, K. M., Salafsky, D. B., \& Hamilton, L. A. (2011). The state of sleep among college students at a large public university. Journal of American College Health, 59(7), 612-619. https://doi.org/10.1080/07448481.2010.520051

Pandi-Perumal, S. R., \& Kramer, M. (2010). Sleep and mental illness. Cambridge;New York: Cambridge University Press. https://doi.org/10.1017/CBO9781139042734

Public Health Ontario. (2013). Mapping a pathway for a Strengths-Based Approach in public health practice Retrieved from https://www.publichealthontario.ca/en/ServicesAndTools/Documents/LDCP/StrengthbasedapproachFinal\%20R eport\%20\%282\%29.pdf

Sanchez, D., \& King-Toler, E. (2007). Addressing disparities: Consultation and outreach strategies for university settings. Consulting Psychology Journal, 59(4), 286-295. https://doi.org/10.1037/1065- 9293.59.4.286

Sexton-Radek, K., \& Hartley, A. (2013). College residential sleep environment. Psychological Reports, 113(3), 903-907. https://doi.org/10.2466/06.10.PR0.113x27z2

Sue, V. M., \& Ritter, L. A. (2007). Conducting online surveys. Los Angeles: Sage Publications. https://doi.org/10.4135/9781412983754

Van Someren, E. (2000). More than a marker: Interaction between the circadian regulation of temperature and sleep, age-related changes, and treatment possibilities. Chronobiology International, 17(3), 313-354. https://doi.org/10.1081/CBI-100101050

Viner, R. M., Ozer, E. M., Denny, S., Marmot, M., Resnick, M., Fatusi, A., \& Currie, C. (2012). Adolescence and the social determinants of health. The Lancet, 379(9826), 1641-1652. https://doi.org/10.1016/S0140-6736(12)60149-4

Ward, K., \& Hawthorne, K. (1994). Do patients read health promotion posters in the waiting room? A study in one general practice. British Journal of General Practice, 44(389), 583-585. Retrieved from http://bjgp.org/

Wong, M. M., Robertson, G. C., \& Dyson, R. B. (2015). Prospective relationship between poor sleep and substance-related problems in a national sample of adolescents. Alcoholism, Clinical and Experimental Research, 39(2), 355-362. https://doi.org/10.1111/acer.12618

Yakushko, O., Davidson, M. M., \& Sanford-Martens, T. (2008). Seeking help in a foreign land: international students' use patterns for a U.S. university counseling center. Journal of College Counseling, 11(1), 6. https://doi.org/10.1002/j.2161-1882.2008.tb00020.x 